\title{
The Effects Of South-South Migration On Economic Development And Its Security Implications
}

\author{
George Andreopoulos, (E-mail: chrights@jjay.cuny.edu), City University of New York \\ Giuliana Campanelli Andreopoulos, (E-mail: andreopoulosg@wpunj.edu), William Paterson University \\ Eliana Antoniou, (E-mail: antonioue@wpunj.edu), William Paterson University \\ Alexandros Panayides, (E-mail: panayidesa@wpunj.edu), William Paterson University
}

\begin{abstract}
Over the last thirty years international migration, defined as voluntary plus involuntary movement of people across borders, has increased enormously. Approximately half of all international migration has taken place within the developing countries and the annual growth rate has been steeper compared to the one of developed countries. Surprisingly, the vast parts of the literature on international migration concentrate on the North-South migration, without considering the South-South one. The scope of this paper is threefold: to analyze the phenomenon of international migration within developing countries, to provide a theoretical framework to study its effect on the receiving country's economic development and to assess some of its security implications.
\end{abstract}

\section{INTRODUCTION}

nternational migration, defined as voluntary plus involuntary movement of people across borders, has increased enormously over the last thirty years. According to the UN at least 120 million people excluding refugees ${ }^{1}$ lived and worked outside their own country in 1990, an increase from about 75
million in 1975; in 2000 the global stock reached 175 million migrants. The average growth rate since 1990 has been about $14 \%$ and higher in the developing countries. Forty per cent of the international migration took place within the developing world. In developing regions, there is a perception that affluent societies are adopting increasingly restrictive immigration policies, accentuating thus the asymmetrical features of a world order more receptive to the free circulation of capital, goods and services than of labor (DSPD/DESA, 2004).

Strangely enough, this South-South phenomenon has not received the proper attention from the literature as well as the media, which place emphasis on the South-North international migration. Needless to say, the South-North migration is mainly based on economic factors and in particular on finding better job opportunities, higher wages and increasing the standard of living.

In addition to the economic, there are at least two more reasons for the explanation of the South-South migration. First are the political/security factors, in particular repression and internal conflict, which are largely responsible for the flow of refugees and internally displaced persons and second the environmental degradation and resource scarcity.

The scope of this paper is to fill the existing gap in the literature by analyzing the phenomenon of international migration within the developing countries, to examine the effect on the development process of the receiving country as well as some of its security implications. For this purpose, we are using the well-known Lewis

\footnotetext{
${ }^{1}$ Refugees are persons who are outside of their country of nationality and are unable or unwilling to avail themselves of the protection of that country because of a well-founded fear of being persecuted for reasons of race, religion, political opinion, or membership on a particular social group.
} 
model, which, in spite of its limitations ${ }^{2}$, seems to be the most appropriate in explaining the functioning of the labor market and economic growth in developing countries. The paper is organized as follows. Section two analyzes the phenomenon of international migration within the developing countries. Section three illustrates the theoretical framework, based on the Lewis model, and discusses the implications of international migration on the receiving country's labor market and economic development and its security implications. Finally section four provides concluding remarks.

\section{THE SOUTH - SOUTH MIGRATION}

International migration is now a global phenomenon and an issue of great concern to countries, international organizations and agencies. Over the last decade, the magnitude and complexity of migration has increased enormously. While the South-North migration can mainly be explained by the economic disparities between the areas of origin and destination, the South-South migration brings two additional reasons. First, environmental degradation and resource scarcity and second, involuntary movements of refuges and internally displaced persons due to political and social factors. In both cases the involuntary component is crucial.

Gould (1994) established a relationship between population migration and the changes in the world political map. In particular, he refers to the end of the cold war, which has been responsible, directly and indirectly, for a new range of regional conflicts particularly in the ex-communist countries, the Middle East and Africa (as exemplified by the cases of Former Yugoslavia, Chechnya, Kuwait, Congo, Liberia, Sierra Leone, Somalia, Sudan, Rwanda, Uganda). The consequences were massive flows of migrants and political refugees towards not only developed but also developing countries and some of them at the very early stages of development.

According to United Nations data on international migration, in any given year during the mid nineties more that four million people migrated across national borders. Of these, more than one and a-half million immigrated permanently in other countries and close to half a million sought refugee or asylum status. The remaining two million sought legal or illegal employment on a temporary basis.

Starting with the involuntary movement of people, if one considers the total number of refugee and internally displaced persons for 2002, it reaches 40 million. Approximately four fifth of all refugees found asylum in Africa or Asia, with the rest migrating to Europe (15\%) the Americas (4\%) and Oceania (0.4\%). Among the refugees, Palestinians and Afghans are the largest group and most of them went to the Near East (Jordan, Lebanon, Syria, Gaza or the West Bank) and in Iran. According to the Global IDP Project, the majority of internally displaced people live in Africa, particularly in Sudan where, for more than twenty years, a civil war has been raging in the southern part of the country. ${ }^{3}$

Turning to the South -South migration due to environmental degradation, in addition to many African countries, one interesting example is that of Bangladesh. Land scarcity and the cycle of droughts and floods have encouraged the illegal immigration of more than 10 million Bengalis- perhaps 20 million including their descendantsto neighboring Indian States.

Finally within the developing countries one can find many cases of international migration due to economic disparities since there has been an increasing economic differentiation among third world countries due to the rapid growth of Middle East oil producers and the so-called Asian tigers. One example is that of people (particularly women) from India, the Philippines, Indonesia, Thailand and Sri Lanka migrating to the Persian Gulf Countries in the eighties. In addition some of the fastest growing economies of Asia like Hong Kong, Malaysia, Singapore and Taiwan attract millions of temporary contract workers from Indonesia and the Philippines.

\footnotetext{
${ }^{2}$ On this issue see Todaro and Smith (2003).

${ }^{3}$ On January 9, 2005, a comprehensive peace agreement was signed between the Government and the Sudan People's Liberation Movement/Army (SPLM/A).
} 


\section{THE EFFECTS ON THE LABOR MARKET, ECONOMIC DEVELOPMENT AND ITS SECURITY IMPLICATIONS}

To analyze the effects of the South-South migration on the receiving countries labor market and economic development we use the Lewis model (1954) since, despite its limitations, it seems the most appropriate one. The main characteristics of the Lewis model are the following. Lewis identifies a crucial distinguishing feature of developing countries - a dualistic structure of their economy. The two major sectors of this economy are the traditional (subsistence) one and modern (industrial) one. The traditional sector includes not only people involved in agriculture but also petty traders, servants, women in household, and other groups without any formal employment. At the very early stage of development (Phase 1), there is an enormous surplus of labor in the traditional sector, i.e., the labor force can be taken out of this sector without any loss of output because the marginal labor productivity equals zero. The modern (industrial) sector is controlled by individuals who possess capital and hire the services of labor. This sector has a higher level of productivity and output expansion than the traditional sector; the speed of the expansion depends on industrial investment and capital accumulation. To these two different sectors correspond two different levels of wages. At a very early stage of development, Phase 1, both wages are exogenously given at the subsistence level (institutional wages). The only difference is that this subsistence wage is higher in the industrial sector mainly due to higher rents, transport cost and a premium for the psychological cost of transferring from the subsistence to the capitalist sector. Lewis claims that this gap is thirty percent; however he does not provide any empirical justification for this figure.

The supply of labor in the modern sector is horizontal at the early stage of development indicating an infinite number of workers willing to work at the existing wage (Phase 1), while at higher levels of development (Phase 2 and 3) becomes upward sloping as in the neoclassical model (see figure 1). (Following the Ranis and Fei (1961) notation,

$\frac{w}{p}$ is the real wage, $L_{L}$ is the amount of labor in the industrial/modern sector, $S_{I}$ is the supply of labor in the industrial/modern sector, $L_{A}$ is the amount of labor in the agricultural/traditional sector, $\mathrm{S}_{\mathrm{A}}$ is the supply of labor in the agricultural/traditional sector, and $L_{T}$ is the total amount of labor in the economy). The same effect, but with a time lag, manifests itself in the traditional sector (see figure 2).

The basic idea for the upward sloping supply curve of the modern sector is that, as this sector absorbs more and more workers from the traditional sector, the labor surplus decreases but also its output is reduced with a consequent increase in the price of food. This is what Lewis defines as the "worsening of the terms of trade" for the industrial sector, which results from a relative shortage of agricultural commodities. The cost of living starts rising and the modern sector requires a higher level of wages to attract workers. This is considered as the second stage of development. A third stage of development is when the supply of labor for the traditional sector also becomes upward sloping. This happens when there is an exhaustion of the labor surplus in the traditional sector and the marginal productivity of labor in this sector exceeds the institutional real wage. At the end of this process the traditional sector can be said to have become commercialized, Ranis and Fei (1961). The equilibrium between the supply and demand curves from now onwards determines the level of real wages and the quantity of employment like in the neoclassical model in both sectors.

At this point, it is interesting to analyze changes in the surplus of labor, which accompany the process of development. According to Lewis the surplus can rise for the following three reasons. First, an increase in the participation rate; particularly important in this respect is the transfer of women's work from the household to the commercial employment. This is one of the most notable futures of economic development. It is important to note that the employment of women outside the household does not depend only on employment opportunities but also on religion, social norms and other social and political factors. Second, increases in the population resulting from the excess of births over deaths. Both the birth and death rates are related to the level of development. There is a wellestablished result stating that a negative relationship exist between the level of development and the death rates, while the relationship between the level of development and population growth is more complex. In particular, the immediate effect of economic development is an increase in the birth rate, but after some decades it begins to grow 
less rapidly. The third source of an increase in the surplus of labor is the unemployment generated by increased efficiency, particularly technical progress.
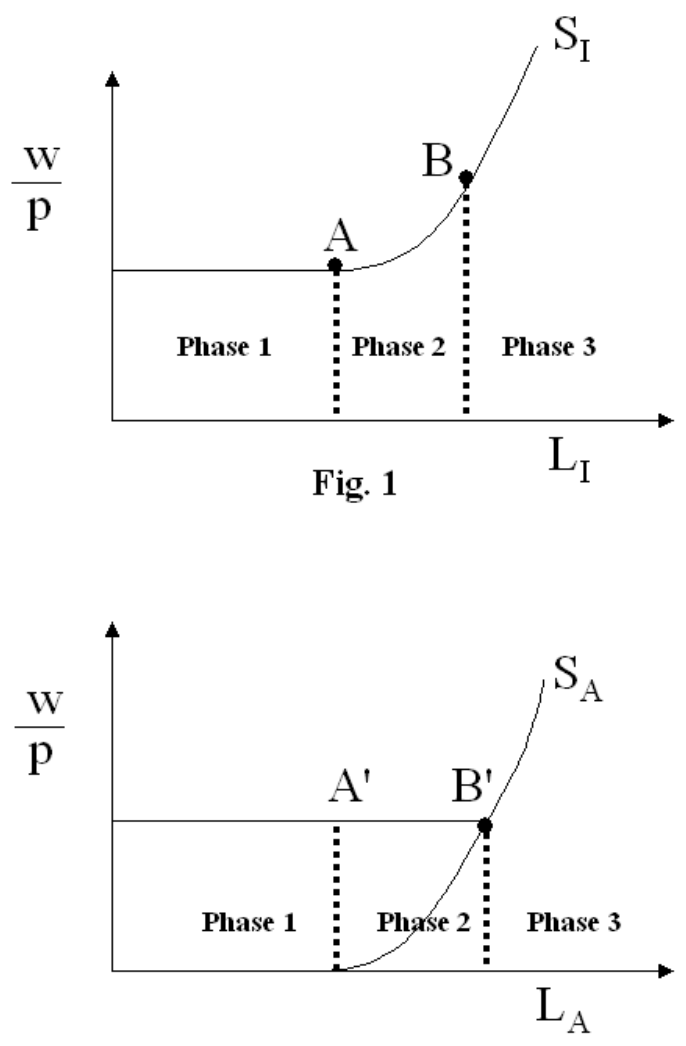

Fig. 2

In what follows it is assumed that all the workers are of unskilled type ${ }^{4}$ the receiving country is at early stage of development (Phase 1) and most of the migrants - mainly of involuntary type - go to the traditional sector. The surplus of labor increases and, ceteris paribus, prolongs the horizontal segment of the supply curve in the traditional sector. The indirect effect will be a delay in the upward shift of the supply curve in the modern sector, as illustrated in figure 3.

As a result of the delay in the upward shift of the modern sector's supply curve, the wage determination continues to be unaffected by demand and supply forces in both sectors. It is worth noting that according to Lewis there is a way to avoid delays in the upper shift of the modern sector's supply curve: a faster growth of the industrial sector. In this case the industrial sector has to absorb more and more labor from the traditional sector, including the migrants.

\footnotetext{
${ }^{4}$ It is worth adding that, on the contrary, the South-North migration might includes a vast amount of highly skilled workers from the developing countries, the so-called "brain drain". According to recent ILO estimates, the brain drain is responsible for the loss of 10 to 30 per cent of skilled manpower in developing countries. There are substantial variations in these numbers among different regions. For example, in the case of Africa, ILO studies indicate that up to 75 per cent of persons immigrating to OECD countries have completed tertiary level education, or equivalent technical training; the corresponding figure from Latin America is around 47 per cent (IMP/UNFPA, 2004).
} 


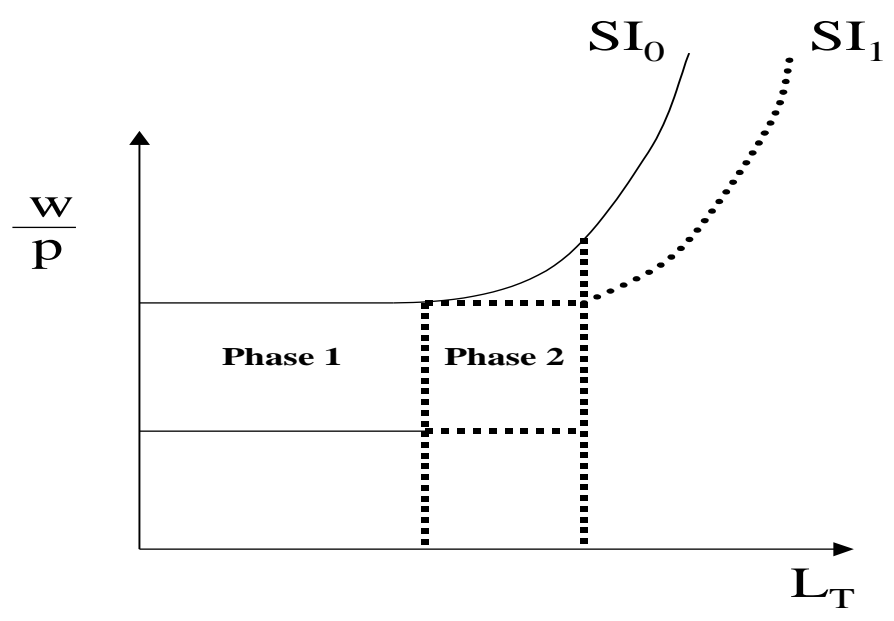

Fig. 3

The amount of the supply shift depends on government policies. In this case, we assume that the government has no interest to increase the already existing enormous surplus of labor unless it does for humanitarian reasons such as helping refugees or internally displaced persons.

A few additional comments on the absorption of refugees and internally displaced persons are in order. Economic and humanitarian considerations are clearly relevant, but the security ramifications of the absorption policy for the host state merit further attention. As several cases in Africa have demonstrated, inability and/or reluctance of host governments to integrate these populations pose security risks. If a government pursues a policy of keeping refugees and IDPs in camps, it must ensure that they remain civilian entities. This means that the camps must be free from armed elements and cannot be used as terrain for military activities (Jacobsen, 2001). However, ensuring the civilian nature of settlements is a difficult task, as the case of the camps in Goma, Eastern Zaire (now Democratic Republic of Congo) and in Tanzania demonstrate (Jacobsen, 2001). These camps were used by the Rwandan genocidaires as places for regroupment, reassertion of their authority vis-à-vis the displaced population, and as launching pads for cross border attacks. In a climate of increasing camp insecurity, humanitarian assistance was diverted and ended up benefiting those responsible for the humanitarian crisis, rather than alleviating the suffering of the victims (Medecins Sans Frontieres/Doctors Without Borders, 1995).

There are other cases in which camps and settlements for displaced persons have contributed to renewed fighting, or to its escalation: the examples of West Timor, of Zambia and of the Parrot's Beak area in Guinea are instructive in this context. The dangers that these developments pose to refugee/IDP safety, and to the security of host and neighboring states have been recognized as a matter of growing international concern. In his second report on the protection of civilians in armed conflict (S/2001/331), the Secretary-General of the United Nations stressed the importance of the early separation of armed elements from civilian populations and reiterated host state responsibility to ensure the protection of distressed and persecuted populations "and the provision of relief and assistance to them." Given the dynamics involved in these settlements, as well as their spill-over effects, a concerted and internationally assisted effort towards absorption/integration could provide both economic and security benefits.

\section{CONCLUSION}

The scope of this paper has been to analyze the phenomenon of international migration within the developing countries and to provide a theoretical framework to study its effects on the receiving country's labor market and economic development and some of its security implications. For this purpose we used the Lewis model in which the 
level of development is crucial to understand the functioning of the labor market while we added migration as an additional source of labor surplus and the role of the government in controlling migration.

The main results are as follows: First, if migrant workers (particularly of involuntary type) move to a country at a very early stage of development they increase the surplus of labor in the traditional sector and by doing so they indirectly delay the process of development of the modern sector. Second, wages continue to remain constant at the institutional level in both sectors. Third, South-South migration can also pose security problems to the host and neighboring states because the camps can be used by armed elements as terrain for military activities. Fourth, a concerted effort to separate the armed elements from civilian population and towards the absorption/integration of this last component can have positive effect, not only on development, but also not host country and regional security.

\section{REFERENCES}

1. Division for Social Policy and Development, Department of Economic and Social Affairs, United Nations (2004), Social Dimensions of International Migration, UN/POP/MIG/2004/8.

2. Ellerman, D. (2003), Policy Research on Migration and Development. World Bank Policy Research Working Paper no. 3117.

3. Gould, W. (1994), Population movements and the changing world order: an introduction, in W. Gould and A. Findlay (eds.), Population Migration and the Changing World Order. New York: John Wiley \& Sons.

4. International Migration Policy Programme and United Nations Population Fund (2004), Meeting the Challenges of Migration: Progress Since the International Conference on Population and Development

5. Jacobsen, K. (2001), African States and the Politics of Refugees: Refugee Assistance as Political Resources (on file with the authors).

6. Lewis, A. W. (1954), Development with Unlimited Supply of Labor. The Manchester School 22: 139-92.

7. Medecins Sans Frontieres/Doctors Without Borders (1995), Deadlock in the Rwandan Refugee Crisis: Repatriation Virtually at a Standstill, http://www.doctorswithoutborders.org/publications/reports/

8. Ranis, G. and J. H. Fei. (1961), A Theory of Economic Development. American Economic Review. 51: 533565 .

9. Ranis, G. (1997), The Micro-Economics of Surplus Labor. Economic Growth Center. Yale University. Discussion Paper \#772.

10. Todaro and Smith (2003), Economic Development. Addison Wesley, $8^{\text {th }}$ edition.

11. United Nations Security Council (2001), Report of the Secretary-General to the Security Council on the protection of civilians in armed conflict, $\mathrm{S} / 2001 / 331$. 